\title{
Insolvency Law Adaptation to the Covid-19 New Challenges: the Process of Destigmatisation and the Focus on the Rehabilitation of Business
}

\author{
Elena S. Koshcheeva ${ }^{1 *}$, Kamilla A. Minnullina ${ }^{1}$, and Julia N. Folgerova ${ }^{1}$ \\ ${ }^{1}$ Vyatka State University, Kirov, Russia
}

\begin{abstract}
The institution of insolvency (bankruptcy) occupies a special place in the state institutions system to support business entities in the recovery process from the crisis, given the selection mechanisms and rehabilitation opportunities inherent in it. Bankruptcy on the global economy scale serves as one of the anti-crisis regulation tools to improve financial and economic stability. The Covid-19 pandemic has actualised the ensuring the bankruptcy law institutional capacity problem by maximising its anti-crisis potential. Given its spread scale, the insolvency law adaptation to the Covid19 new challenges is a challenge faced by all legal systems without exception. The findings of this study reveal that fragmented and uncoordinated national responses have common trends caused by the unity goal of minimising economically and financially destructive effects of the pandemic. This study objective was to identify the most effective strategy for the bankruptcy institute modernisation, which solution is based on the elements comparative analysis and convergence methods. In conclusion, the bankruptcy institute development basic tendencies and patterns have been revealed. Their analysis has allowed designating the legislation perfection most effective and perspective strategies in this sphere, which are determined by the course to aim at its anti-crisis potential development. Keywords: Covid-19 new challenges, the process of destigmatisation, rehabilitation, insolvency, bankruptcy.
\end{abstract}

\section{Introduction}

The covid-19 pandemic had a negative impact and revealed vulnerable points in the social and public health spheres; it is also paralysed business activity and had unprecedented economic consequences, comparable in scale to the crisis of the 1930s [1]. The phenomenon of global economic interdependence determines the tendency towards similar responses to the spread of the virus eventually. The phenomenon referred to as the «copycat coronavirus policies» resulted from regulatory emulation [2]. This study demonstrates that these processes are also reflected in the institute of bankruptcy.

The article attempts to systematise the responses implemented by states to minimise the pandemic negative economic effect, directly reflected in the insolvency institute legal

${ }^{*}$ Corresponding author: usr22709@vyatsu.ru 
regulation, to identify patterns and trends. This study objective was to identify the most effective strategy for the bankruptcy institute modernisation, which is based on the comparative analysis and convergence methods.

\section{The institute of bankruptcy as a tool of anti-crisis regulation}

In conditions of economic downturn, the legal regulation of insolvency deserves special attention from the point of view of its anti-crisis potential. The most dynamic development of legislation in this area is during the crisis. Given its spread scale, the insolvency law adaptation to the Covid-19 new challenges is a challenge faced by all legal systems without exception. Insolvency laws have changed in Germany, Great Britain, Italy, the USA, Poland, Colombia and other states, including Russia [3]. This article attempts to systematise and structure the Government's response at the national level to the institution of insolvency, aimed at minimising the negative consequences of the pandemic. The analysis allows us to demonstrate that disparate, uncoordinated measures have common trends and patterns, which are determined by the course of anti-crisis potential development of the legislation in the field of bankruptcy (insolvency).

The institution of insolvency (bankruptcy) occupies a special place in the state institutions system to support business entities in the recovery process from the crisis, given the selection mechanisms and rehabilitation opportunities inherent in it. Bankruptcy on the global economy scale serves as one of the anti-crisis regulation tools to improve financial and economic stability [4]. This special institution importance is determined by its main functions: bankruptcy prevention and avoidance under temporary economic downturn conditions; corporate solvency restoration with economic feasibility and viability to viable entities, through the crisis exit tools provision; the insolvent entity liquidation takes into account all parties (stakeholders) interests, which implies the debtor's assets effective and fair distribution.

On this basis, the bankruptcy institution provided the mechanisms inherent in it are adequate, can act as a powerful tool to protect business entities affected by the COVID-19 pandemic negative economic consequences. It is worth agreeing with the opinion that «bankruptcy is not a problem, but a solution especially for large companies» [5]. In addition, pandemic crises pose the massive corporate bankruptcies threat and catalyse inefficient insolvency mechanisms problems. Based on the above, the Covid-19 pandemic has actualised the ensuring the bankruptcy law institutional capacity problem by maximising its anti-crisis potential.

\section{The bankruptcy institution transformation to minimise the pandemic negative economic impact}

\subsection{Emergency measures to prevent bankruptcies a massive wave}

The pandemic response first phase was characterised by fragmented, uncoordinated measures designed to prevent a massive wave of bankruptcies and to allow time for businesses to recover [6]. Measures at this stage were time-limited and subject to cancellation (or review) depending on the pandemic scale and impact in a particular country.

One of the first measures taken in jurisdictions a number is the provisions' suspension imposing an obligation on controlling persons to initiate bankruptcy proceedings if there are objective insolvency indications. Most states suspended bankruptcy procedures initiation by creditors, including Russia, the so-called moratorium on bankruptcy. However, concerning creditors' rights to apply for bankruptcy, states a number followed the not prohibition path 
but correction towards insolvency threshold increase concerning the claims' amount and periods during which they are not fulfilled. In Singapore, for example, the amount of insolvency was increased tenfold and the period within which the debtor failed to meet the claim was doubled. Indian law initially restricted the creditors' rights to initiate bankruptcy proceedings, but a moratorium was subsequently imposed [7]. Despite the different approaches, in essence, they are defined by a common objective, which is characterised as taking into account the negative pandemic impact in assessing the introducing bankruptcy procedures reasonableness concerning a person.

The first phase emergency response measures, although fragmented and uncoordinated, aim to prevent bankruptcies from a massive wave by giving business entities a certain period to recover. There is no denying the differences in the ongoing reforms some elements, for example, most countries took the existing regulations optimisation and modification path (on a temporary or permanent basis), in other states, support measures were taken by introducing special regulations. Although individual elements differed from jurisdiction to jurisdiction, in essence, they all had the same objectives, by restricting or prohibiting the bankruptcy procedures initiation.

The moratorium is «postponement a kind» concerning entities with insolvency signs due to the circumstances exceptionality and essentially a rehabilitation mechanism. However, its introduction has aggravated the debtor and creditors balancing the interests' problem. In particular, it has brought to the fore such a measure admissibility issues in dishonest debtors respect, as well as its rationality in person respect, whose crisis financial condition arose before the pandemic. In Russia, to the difficulties associated with identifying which companies have been affected by the pandemic, the Supreme Court explained that countering to abuse these benefits by the debtor is possible only on the mechanisms «ex-post» basis, directly in the bankruptcy case, after the moratorium lifting.

The measures in this phase were characterised by a time limit. Due to the termination of their operation in most states, their consideration does not seem relevant. Moreover, their effectiveness from the standpoint of economic stabilisation is already being evaluated by experts [8]. At the same time, already at this stage, the processes of convergence of legal regulation are manifested due to the modelling and implementation of the most effective strategies for responding to the spread of the pandemic. The so-called response emulation, which consists in the similarity of response measures, despite its preferential consideration in the context of the social sphere, is thus reflected, among other things, in the legal regulation of insolvency.

Following this approach, the further development of legislation in this area is also characterised by common patterns that allow us to identify common trends.

\subsection{Subsequent reforms to "smooth the insolvency curve.»}

The measures taken at the initial stages had a stabilising effect. However, the crisis phenomena determine the reforming of the legislation on bankruptcy necessity in increasing its anti-crisis potential direction. Experts predict an increase in the corporate' bankruptcies number, which determines the legislation ensuring practical legal regulation task in this area, which provides for procedures optimisation and its unique mechanisms adaptation to new challenges.

The response second stage is already characterised by greater focus and consistency, which main task is to smooth the bankruptcy curve. This stage implies reforming the legislation on bankruptcy to increase its anti-crisis potential, optimisation, adaptation to the crisis phenomena caused by the pandemic.

As the Covid-19 spreading a result, the real economy sector and, in particular, small business entities turned out to be in the most vulnerable position. This specificity determined 
the general tendency to strengthen the pro-debitor component and the focus on increasing the efficiency and effectiveness of rehabilitation mechanisms.

\subsubsection{Improvement rehabilitation procedures effectiveness}

Given that the bankruptcy anti-crisis potential is primarily determined by the rehabilitation procedures effectiveness, their improvement is one of the law reform main trends, through procedures simplification and conditions for their introduction. Thus, in countries, a number (the USA, Singapore) the rules on thresholds of creditors' consent for the procedures introduction and financial reorganisation plan approval were revised or abolished. Improving the effectiveness of rehabilitation procedures is based on providing debtors with some of the advantages (especially in terms of flexibility and minimal court involvement) [9].

Low-efficiency the rehabilitation procedures problem in the Russian legal system, which is caused by pro-creditor concept prevalence. Reforming the legislation on insolvency in strengthening its rehabilitative orientation direction was and remains a topical issue, widely discussed in the doctrine [10]. It is necessary to admit that the crisis phenomena caused by the pandemic accelerated its resolution. At the moment the large-scale reforms draft to the legislation on bankruptcy is under consideration, providing radical changes of rehabilitation procedures.

\subsubsection{The preventive restructuring mechanisms introduction}

Due to the high costs of bankruptcy cases, the development of bankruptcy prevention tools is one of the urgent tasks. In the mass bankruptcies forecasts view, one of the reform key areas is characterised by the preventive restructuring mechanisms introduction. These tools should help to reduce the burden on the courts, as well as reduce the costs associated with bankruptcy proceedings. Recommendations to introduce preventive restructuring mechanisms in the insolvency institution were developed by the European Union back in 2019 , but the crisis phenomena prompted lawmakers to enshrine them legally [11]. European states a number are adopting special rules on restructuring, providing for the possibility for entities in financial distress to restructure debts through an agreement with creditors outside the bankruptcy framework. The Dutch bankruptcy law (Faillissementswet, DBA) introduced the procedure «Wet homologate underhand akkoord» based on the preventive restructuring American model, also in Germany, the Government accelerated the adoption of the Directive [12].

In addition, States should encourage the contractual settlement of relations between creditors and the debtor, which is especially important for small companies with concentrated debt structures. In Russian practice, the institution of a settlement agreement has replaced other rehabilitation procedures, due to more «soft» conditions and requirements for its conclusion.

\subsubsection{Special (simplified) regimes establishment concerning micro-, small-, and medium-sized enterprises (MSMEs)}

Taking into account the fact that in crisis conditions, the bankruptcy highest risks have (MSMEs), one of the trends is characterised by the bankruptcy procedures special (simplified) regimes establishment concerning them. This regime specific is to establish a faster and simplified procedure to minimise costs. For example, new rules for microenterprises have been introduced in Colombia. In Australia, a new insolvency regime for MSMEs came into force on January 1, 2021. The recommendations developed for simplified insolvency procedures rules for small and medium-sized enterprises are the 
international organisations' responsibility (UNCITRAL, the World Bank) [13]. In jurisdictions where such rules are already in place (USA), attempts are being made to expand the subjects range falling under special treatment, in particular, such rules extension to include medium-sized enterprises [14].

\subsubsection{The process of destigmatisation of insolvency}

Reducing the stigma of insolvency proceedings is also a policy recommendation suggested by the World Bank and UNCITRAL. The Covid-19 pandemic has caused the spread of the concept that any corporation can meet with a financial crisis. Insolvency is not always due to unfair actions; respectively, business failure could not be punished. This approach contributes to the understanding of insolvency as a tool for business recovery and not only as a liquidation mechanism. Moreover, accordingly, encourages corporations to turn to its mechanisms to get out of the state of crisis.

The most striking example is the change in the «crisis» definition in Italian legislation, which is now defined as a significant economic and financial imbalance. In the legislation of the USA, the term «debtor» is changed than the word «bankrupt» to refer to insolvent companies.

An attempt to reduce the stigma is aimed at analysing the institution of insolvency as an essential part of the entrepreneurial system. An insolvency legislation can actually also for solvent firms. Many studies indicate the need to distinguish between the institutions of insolvency and restructuring, which are components of a single «law of corporate distress» [15]. This approach expands the institutional opportunities of bankruptcy as an anti-crisis regulation tool, amplify it the ability to affect the levels of entrepreneurship and economic growth in a country.

\section{Conclusions}

The Covid-19 pandemic spread predetermined essentially new challenges for the legislator in the insolvency legal regulation sphere. Responses to the pandemic negative economic consequences in the bankruptcy institution serve as the legal convergence processes a reflection due to the goals and objectives uniformity and the need to identify the most effective model (strategy) to strengthen this institution anti-crisis potential. Thus, despite all the negative consequences of the pandemic, the insolvency institute context can be considered positively, as evidenced by the following arguments. First, the economic crisis phenomena catalysed bankruptcy legislation deficiencies and problems and contributed to its more dynamic reform already existing in the political agenda of many countries. Second, the pandemic facilitated of harmonisation and legal convergence process with undeniably positive effects.

The foreign countries experience in adapting national bankruptcy laws to the pandemic crisis makes it possible to identify the reform most promising areas: improving the effectiveness of rehabilitation procedures, the preventive restructuring mechanisms introduction, special (simplified) regimes establishment concerning micro-, small-, and medium-sized enterprises (MSMEs). Moreover, the economic instability conditions predetermined the insolvency institution concept global revision towards the pro-debitor orientation. The bankruptcy destigmatisation advantages are manifested in the institution liberalisation and increasing its rehabilitation component effectiveness.

\section{References}


1. J. Sapir, Economics and Mathematical Methods, 3 (56), 5-25 (2020).

2. A. Alemanno, European Journal of Risk Regulation, 11(2), 307-316 (2020).

3. A Gurrea-Martínez, Insolvency Law in Times of COVID-19, Ibero-American Institute for Law and Finance, Working Paper 2/2020, (available at: https://ssrn.com/abstract=3562685).

4. O.A. Lvova, ECO journal, 6, 83-102 (2019).

5. J.A. Ellias and G. Triantis, Congress is ignoring the best solution for troubled companies: bankruptcy, Fortune, 2020 (available at: https://fortune.com/2020/05/14/bankruptcy-cares-act-aid-coronavirus/).

6. N. Shchukina, V. Varfalovskaya, A. Bekaeva and L. Salinas, Economic Annals- XXI, 12 (187), 90-98 (2021).

7. A. Jindal, IBC (Amendment) Ordinance 2020: Straddling Between Manoeuvre and Ambivalence, IBC Laws Leave a comment, 2020 (available at: https://ibclaw.in).

8. J. Payne, An Assessment of the UK Restructuring Moratorium, 2021 (Available at: https://ssrn.com/abstract=3759730).

9. S. Madaus and F.J. Arias, European Company and Financial Law Review, 3-4 (17), 318-352 (2020).

10. V.N. Alferov, MIR, 2 (26), 180-190 (2016).

11. E. Ghio, J. Gant, G. Boon, D. Ehmke, L. Langkjaer, and E. Vaccari, Harmonising Insolvency Law in the EU: New Thoughts on Old Ideas in the Wake of the COVID-19 Pandemic. International Insolvency Law Review, 2021 (Available at: https://ssrn.com/abstract=3855429).

12. S. Madaus, A.K. Wilke and P. Knauth, Int. Corp. Rescue, 17 (1), 21-28 (2020).

13. A. Gurrea-Martínez, Implementing an Insolvency Framework for Micro and Small Firms, International Insolvency Review, 2021 (Available at: https://ssrn.com/abstract=3715654).

14. W. L. William Norton III \& J. B. Bailey, Emory Bankruptcy Dev. J. 383, 383-393 (2020).

15. S. Madaus, European Business Organization Law Review, 19(3), 615-647 (2018). 